\title{
The Power of Micro Urban Structures, Theory of EEPGC - the Micro Urban Energy Distribution Model as a Planning Tool for Sustainable City Development
}

\author{
Štefan Tkáč \\ Technical University of Košice \\ Civil Engineering Faculty, Institute of Architectural Engineering \\ e-mail: stefan.tkac@tuke.sk
}

\begin{abstract}
To achieve the smart growth and equitable development in the region, urban planners should consider also lateral energies represented by the energy urban models like further proposed EEPGC focused on energy distribution via connections among micro-urban structures, their onsite renewable resources and the perception of microurban structures as decentralized energy carriers based on pre industrialized era. These structures are still variously bound when part of greater patterns. After the industrial revolution the main traded goods became energy in its various forms. The EEPGC is focused on sustainable energy transportation distances between the villages and the city, described by the virtual "energy circles". This more human scale urbanization, boost the economy in micro-urban areas, rising along with clean energy available in situ that surely gives a different perspective to human quality of life in contrast to overcrowded multicultural mega-urban structures facing generations of problems and struggling to survive as a whole.
\end{abstract}

Key words: energy, sustainability, urban planning

\section{General Introduction}

Research proposals dealing with the urban planning problems of human dwellings are mostly concentrating around the macro urban sphere which in nowadays global development era represents the centre of many questions including social, economical, psychological, transport and energy related etc. Thus creating a complex challenge that could not be anymore solved by a simple general planning approach. Cities as we know them today were build according to the particular planning systems coming from the local believes, traditions, opinions, needs and well known planning models (from Blueprint planning until various forms of Participatory planning). The question for the future development of our cities that was anticipated in the famous $10^{\text {th }}$ Venice Biennale of Architecture with the light motif concerning the Cities, architecture and society became more frequently discussed as the world crossed seven billion population milestone in 31 . October 2011. The cities were built mostly in 
centralized patterns, the question is, will these certain patterns work even in the next few decades until the next population boundary? Would we or are we already facing the consequences of the John B. Calhoun famous rat experiment or more often pictured society breakdown and barbarism revival as a future vision of contemporary filmography? Urgency for different planning procedures, different society insights need to emerge. According to WHO in 2020 more than $60 \%$ of the world population will live in the urban areas, even in less developed countries and this number will only rise. Currently the estimated annual growth is $1.84 \%$ and should slow down to $1.44 \%$ between 2025 and 2030 which reflects a slight drop mostly because of the lifestyle we are exposed to, but despite the rising pressures on the environment, global food supplies, and energy resources the UNFPA argue with 10 billion in 2083. $21^{\text {st }}$ century thus holds the urban planning threshold, what we do as urban planners today will reflect as a consequences in the future society form because it is exactly the urban environment that forms the society from its very beginning. The main question in this paper is whether city represents the only urban structure that participates in urban growth?

\section{Introduction to the EEPGC}

The EEPGC (Efficiency Electric Power Grid Circles) theory proposes a new energy distribution model as a part or the overall strategy planning process. EEPGC combines prof. Nikos A. Salingaro's studies about the urban morphology perceived as groups of fractals and networks, the connection bonds of the micro-urban structures recognized as the Small-world or the Scale-free network concepts of the urban forms and their properties mapped by using the Urban Network Analysis Toolbox for ArcGIS software with application of the Jeremy Rifkin's futuristic, but momentarily feasible vision concerning micro-urban structures as decentralized energy carriers. The theory proposes the RES (Renewable resources) potential for distributed generation, mapped in the micro-urban structures. These structures are always variously connected when part of greater patterns, generally they could be found in direct knot with the city, respectively with a central energy source as well as in a minor bonds between each other. The EEPGC, applies virtual "energy circles" around the city, perceived as the major centralized energy source (and the major consumer at the same time) and using preindustrial scheme considering city supported by the surrounded micro-urbanism. The possibility of creating the "energy circle communities" in vicinity of the city with their future integration perspective into the constantly growing city structure appears as a viable option for city to grow equably, likewise its consumption rate. These "circular lines" represent the distance at which the transported energy between villages and city could still be considered as sustainable. The EEPGC distribution system represents a proposed distribution idea orientated toward the micro-urban development counting with the small urban distances between the micro-urban structures. These structures could be found in clearly readable form especially in Europe and thus it is easy to distinguish their boundaries, however in most of the World micro-urban areas, they are mostly complex issues especially in the fast developing countries where micro-urban structures must be tracked backward or the division might be done by the individual development projects made over the last periods. In these cases the above mentioned theory of fractals and networks is at the right place. 


\section{Post industrial energy model with roots in pre-industrial society?}

In the pre industrial society the role of a village was indispensable for daily burger's life. Villages representing the micro-urban sphere of that time show cities as a consumer supported by its chains. Feasibility of this model in nowadays era becoming discussed again as the city growing rapidly and more than $50 \%$ of the World population lives in urban areas consuming more than $60 \%$ of the global energy demands. But as the distances shorten the target goods for trade became the energy in terms of energy supplies. Smaller structures are more likely to become independent hence energy zero or energy positive. Indeed there are already several energy positive villages like Feldheim or Sonnenschiff project in Freiburg im Breisgau both in Germany, but on the other hand there is still $1 / 5$ of the overall World population living in the dark. If macro-urban scale impact is concerned, the micro-urban structures - villages consisted of micro-urban units - mostly individual dwellings could represent the LCPG Local Community Power Grid as pictured on figure no. 1 below. In case of energy overproduction in the LCPG if the distance to the city is viable for transport then direct support, energy storage for later use or the emergency scenarios like coverage of the local black outs might be feasible. According to the EEPGC the villages surrounding the city are called the "satellite" villages. These "satellite" villages form circles with radius equals to efficient distribution distance in low voltage wiring that is calculated by the energy losses in wires which usually represents $10 \%[1]$. Each circle could be perceived as the Small-world network, produces energy for itself and trades energy among the villages at the same level. Additionally in case of energy overproduction, the primary circle usually includes largest villages and is the closest to the city centre so it plays the role of direct city grid support ("opposite grid flow") with the lowest loses in wiring in emergency scenarios or off peak support, secondary, tertiary etc. are playing the role of backup and support for themselves and the primary one as well. All villages play the role of energy storages for short or long term period. Assuming that villages promote micro-urban renewable policy individuals will be able to create micro-power stations directly form their own houses. The RES micro technology is progressively known among the general public and already market available [2]. Houses thus could becam energy efficient or even energy positive counting in the whole lifespan of the modern house due to constantly improving modern methods of construction [3]. Detached family house is already capable of producing home energy from available renewable resources for their inhabitants and thus under regulated development support LCPG from which it could be distributed to the next village or directly to the CPPG - City Public Power Grid. Energy coming from water, wind, soil or sun exhibits clean renewable source. Once applied it in the nowadays urban communities, it could certainly support the set of proven positive effects a green design has on human in general [4]. This "little" community inclusion due to individuals may also contribute in boosting the micro-urban life, cohabitation with the surrounded environment, trade and its economy; even the high voltage wiring could change into low voltage as the distance shortens.

\subsection{Micro to macro...}

Nowadays urban energy distribution proposals are usually focused on the city or macro-scale. As the city grows, the centralised energy regulation has become more difficult, but as stated before is really city the only urban unit that is involved? 


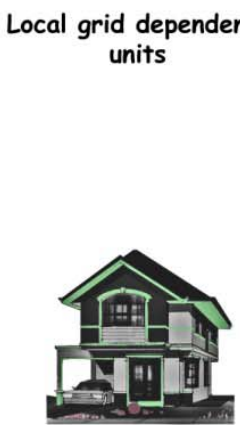

A
Local grid dependent units using one renewable resource at minimum
Energy independent units. Using two renewable resources at minimum.

Renewable resource community Local community power grid based on individual units (LCPG)
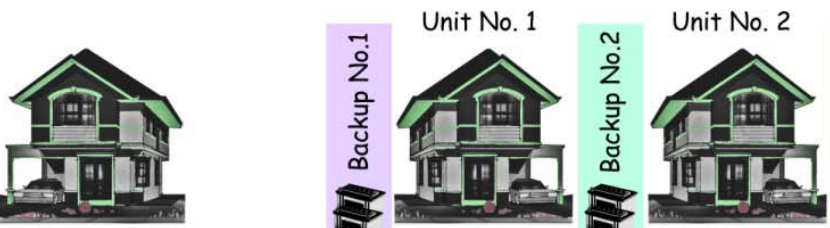

\section{C}

optional energy balance \& trade among the units (LCPG)

\section{LPPG to}

individual units not connected in renewable resource community

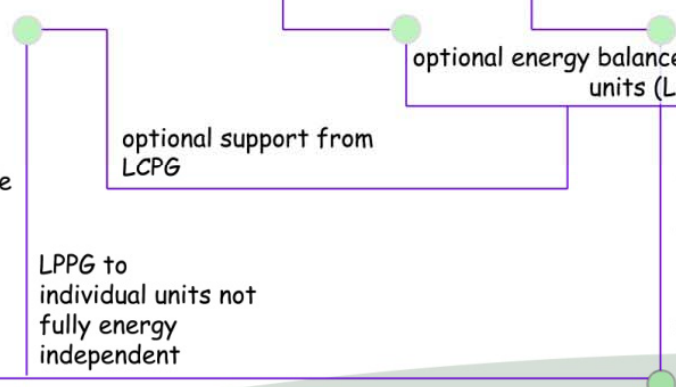

LCPG to LPPG

basic support if

overproduction in LCPG

if not needed - placed in

local/ personal

storage (Backup)

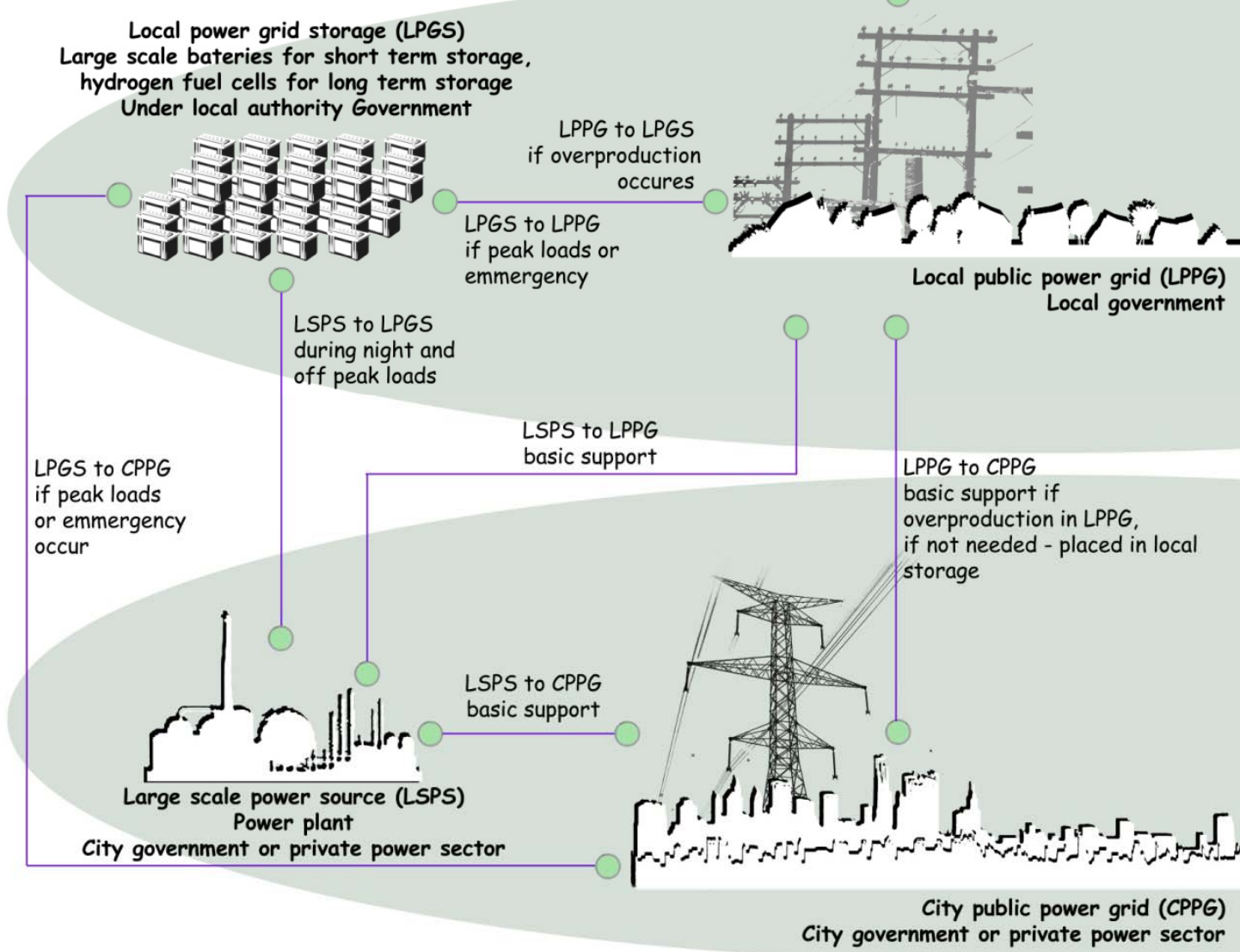

Figure 1: The idea of "satellite" villages and "opposite grid flow" (grid management and energy balance policy) 
Energy storage within the micro-urban region could be provided at the whole micro-urban structure level as a local mass storage represented by the set of large scale batteries for short demands, micro-pumped storage, closed hydro-circular system or according to the Rifkin's Hydrogen economy the hydrogen conversion, usable for the hydrogen fuel cells for long term applications or emergency scenarios. Hydrogen could be also sold as an alternative fuel for the local buses or cars for transportation means often needed in the remote areas. Excessive energy could be turned into distilled water by reverse osmosis that could be sold as well or turns into oxygen and hydrogen later plus distilled water, after adding minerals and ions might be used as drinking water too which would be of great use in island countries, remote areas, farms or individual housing, where the lack of drinking water is noteworthy and tap water might cause serious health damage in the near future. On the micro-urban structure level, energy storage is usually represented by standard batteries as the hydrogen requires special attention, but as the systems are developing constantly and the general awareness too, the hydrogen off-grid energy systems or hydrogen hybrid renewable energy systems (HRES) are already commercially available for single houses as well. This could create new job opportunities in micro urban regions and bring a more balanced economical growth in the whole country.

\subsection{Interaction between the city and village}

Since its beginnings, the urban micro sphere was a part of the urban structure as a whole which supported the greater and more complex structures formed from human dwellings, whether it was in the form of goods, materials or natural resources. Pre industrialised era is exactly defined by this mutual cohabitation. After the industrial revolution the main traded goods became energy in its various forms and those goods were and still are usually imported and only few of the micro-urban structures benefit from this model. Particularly those that posses local natural storages of fossil resources. Those structures evolves really fast and as a matter of fact most of them depredates pretty fast too as the resources were replenished or demands have changed throughout the time. There are lots of examples of abandon mines together with abandoned ghost towns or cities that were once a vibrant resource facility e.g. Japanese Hashima Island or abandoned Jinguashi mine in Taiwan. By boosting the economy in micro-urban areas through the renewable energy systems, those micro-urban structures might find a new importance as they use to have in the past. Typical traditional markets full of arts and crafts products, handmade high quality products typical for certain location etc. Natural human scale decentralised urbanisation rising along with the potential clean energy available at the place will surely give a different perspective to human quality of life in comparison with overpopulated multicultural mega-urban structures dealing daily with tons of problems and struggling for survival. Centralisation got a certain level where it reaches its peak and then it is simply dying out because it could not face the tons of problems, just like the rat community in previously mentioned famous, but many time forgotten John Calhoun's 28 months experiment in the $60^{\prime}$ s[5]. Human race keeps on building centralised systems not only in architecture, but there is still a turning point where they realised that they can't manage it anymore. Mega cities and mega structures are colossal waste of money, energy and material resources of this planet that could be definitely divided more wisely and widely. Overpopulation issues are on the contrary mostly bound with the mega structures rather than 
micro-urban areas. Investing in long term micro-urban policy might be the key to a healthier social life, interpersonal behaviour and also step by step healing solution for the sick cities.

\section{Calculation of the EEPGC}

\subsection{General factors}

General calculation of the EEPGC is based on 3 factors: Distance, Transportation, Losses. Distance represents the connection length between the city and particular village or village to village distance. Transportation refers to minimization of the generated energy that transits between the urban structures at both mentioned connections and losses show the percentage of the energy lost in the exchange process according to distance.

\subsection{System within the energy circles}

City is assumed to be surrounded by several villages referred to as micro urban structures and already has bonds with some or all of them. Step one is to establish every existing connections between the city and each individual structure as well as between the structures itself. In case of more complex urban structures a previous analysis of the individual structures in micro urbanism must be done. Distance is calculated according to the economically viable energy transport. If the primary circle radius between the city and the furthest village is unprofitable it is important to search for alternative village to village bond as it might create more energetically interesting correlation and every further village is included into the secondary circle. If it comes to bonds generally there can be found 3 bond modules (Fig. 2 below) with 3 modifications. Partially indirect module consists of village to village to city connection, indirect module village to village and direct module including village to city connection. Each module can work in 3 modifications combining village as an energy generator and village as an energy storage, energy generator and energy generator or energy storage in bond with another energy storage.

\subsection{The primary circle within...}

The connections in primary circle are based on proximity of micro urban structures, based on efficient transportation or traded consumables, in case of EEPGC the energy. A Small-world or Scale-free networks features could be observed here as the villages are in certain radius and they are already connected on many levels like transportation, telecommunication, trading, cultural, energy supply etc. However the connections are not based on RES energy correlations. These connections could happen inside the village (micro urban unit to micro urban unit, house to house support level), between two or more villages sharing energy interests (cluster formed from micro urban structures) and between clusters. These are the moments where the Small world networks could take place as some villages could be connected with another purely on energy exchange level thus this kind of connection could be considered as out of the regular network hierarchy or one village simply posses larger RES source then others involved in the cluster and in this case a Scale free network with single hub could be observed. All described examples are in close energy exchange interaction with the 
city as they are more likely to become part of it.

\section{The EEPGC case study}

Since EEPGC theory is still developing there has been several theoretical application into real conditions by establishing the electrical energy transportation losses or electric vehicles radius for the hydrogen bottles delivery service. One of calculation of the EEPGC viability comparison is the case study in Slovakia and Taiwan where aaccording to the SEPS, a.s. (Slovenská elektrizačná prenosová sústava, a.s) [6], the total overall deployed length of distribution lines in Slovak Republic represented $2816,829 \mathrm{~km}$ in 2011 and the volume of distributed energy per year 2011 was equal to $28341,708 \mathrm{GWh}$ with $293,993 \mathrm{GWh}$ reported loss in wires which is $0.104 \mathrm{GWh}$ per km per year, not counting in differences in losses and voltage of wiring. Supposing that one average Slovakian house with 4 members family consumes $3500 \mathrm{kWh}$ per year we are talking about a loss of approximately 30 houses per circuit km. In Taiwan according to the Taiwan Power Company Sustainability Report 2012 [7], the total distribution lines span of Taiwan island equals to $357,000 \mathrm{~km}$ at the end of the year 2011. The total overall transmitted energy that was sold to costumers equals to $198,637 \mathrm{GWh}$ with $4,76 \%$ loss reported which represents about $14,405 \mathrm{GWh}$ per year. That is approximately $0,040 \mathrm{GWh}$ per $\mathrm{km}$ per year. Counting with the average house consumption equal to Slovakian detached family house, the losses in Taiwanese lines could cover 11 family houses in average per one $\mathrm{km}$ per year. Even though Taiwanese energy giant Taipower aims to enlarge its distribution system to 2,370 circuit $\mathrm{km}$ in nearest decade as a conclusion the Slovakian distribution system is much longer so even the line losses are equal to $1,037 \%$ the overall power losses are higher because of the distance power needs to be transported to. Electrical energy distribution rule points out - that the further the power needs to be transported the higher the losses will be even when the superconductors will be used. The possible avoidance of the losses in the system might be application of the Smart grid technology that is already in consideration in Taipower and already installed in Slovakian neighbours the Czech Republic in several areas. Another long term plan might be decentralisation of power sources and thus giving chance to RES (Renewable resources) locally available plus development of local (Micro-urban) smart grid systems (previously mentioned LCPG) that would remarkably enlighten the peak loads for national grid and also create space for regional development plus it will help to push down high unemployment rate (currently over 14\% / 2013 [8]) in remote regions locally vary from $10-20 \%$ [9] or even higher in Slovak Republic.

\section{Implementation}

Before an urban energy distribution model could be fully operable and serves its purposes there must be several calculations done first. Firstly, urban research, RES availability, adjusting the distance and calculating the losses for each particular village. If it comes to any kind of change in urbanism, it is always easier to implement the new ideas in small groups than move huge masses or change a system that people are used to for many years. Research focused on micro-urban energy potential should be in this century embedded in the strategic 
plan for each village as it is a source for many future developments, but mostly for possible autarchic existence.

\subsection{Urban research}

Urban research should be focused on the general and overall conditions of micro-urban structures, counting in the conditions of micro-urban units, their conditions, their capacity (inhabitants, consumption, possibility to apply RES micro-urban devices etc.), facilities, services, inhabitants information for RES, their will to develop RES program and participate in community planning or workshops, possible dwellings expansion, any available public buildings, operable vs. inoperable, property rights and possible administration obstacles at all levels, distances from the nearest micro and macro-urban structure, trying to establish the centre or historical core and boundaries of the micro-urban structure.

Primary energy circle

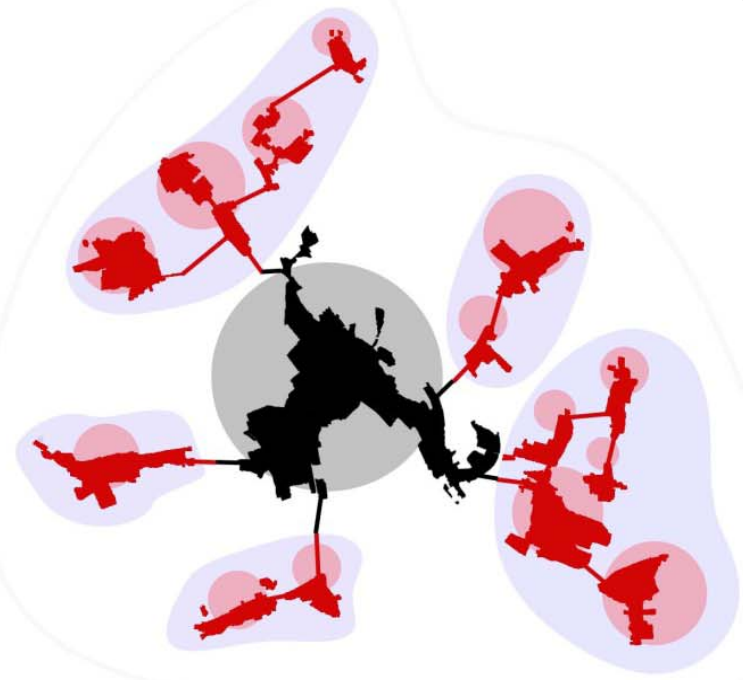

Chain of villages within the energy circle showing various modules incorporated in the EEPGC
Partially indirect module (village to village to city)

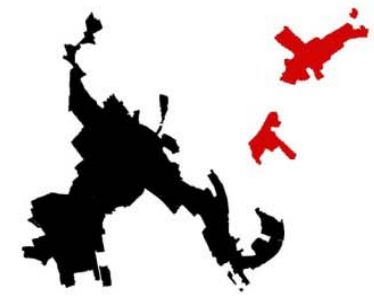

Indirect module (village to village)

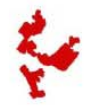

Figure 2: System within the energy circles explanation of the modules

These "energy positive" villages could in terms of energy support other structures (neighbour village, directly city grid) directly. Another example is presented with probably more common villages which population is higher than RES, however they are able to produce some energy that will lighten the overall public grid that originally supports the villages thus this energy could be used further in other structures. This villages support the grid indirectly by lowering its electrical energy demands. Distance between the village and the city or village 
and the closest village might be thus calculated firstly based on a direct or indirect support described above, and then by looses. For example that village which is now fully dependent on the public grid coming from the centralised power source would be more sufficiently supported by the next closest village that is energy positive so that the overall annual line losses could be used somewhere else or in the village itself for energy conversion to hydrogen as a possible energy storage that could be then transported, sold or boost the local businesses.

\section{Start up implementation - path towards the sustainable development}

To conclude, after all the calculations for a particular region, the whole distribution model could start to gain a practical form through a step by step offer for the application of RES micro-urban devices to the individual houses in the city's nearest villages and villages closest to high voltage wires. Assuming that each individual house that will apply the RES microurban device could save at least some energy, that energy could stay in the grid and serve further houses in the next available village. As the city grows and the first circle of the villages might become the part of the city the second circle become the first and the scenario could repeat so that the overall development gets a sustainable dimension and the city could grow in larger scales, but all the time it will be attached to some degree to the micro-urban region that (village, micro-urban structure) will be already prepared as the energy efficient structure and so that next development could take place, "because the ability to think at least a generation ahead is a mirror reflection for an intellect based nation, significant for the "hitech-nocratic" $21^{\text {st }}$ century".

\section{Acknowledgements}

The Author wishes to thank first assoc. prof. Ing. Zuzana Vranayová PhD, prof. Ing. Peter Horbaj, $\mathrm{PhD}$, assoc. prof. Yen, Ke-Chin $\mathrm{PhD}$, assistant prof. Tsai, Yi-Ying $\mathrm{PhD}$. for the constant encouragement, support and advisement. The presented paper is component of the project VEGA no.: $1 / 0202 / 15$ - "Sustainable and Safe Water Management in Buildings of the $3^{\text {rd }}$ Millennium" and NSP National Stipend Fund of Slovak Republic.

\section{References}

[1] Kolcun, M., Chladny, V., Varga, L., Bena, L., Ilenin, S., Llescinský, P. \& Mester, M. (2005). Analysis of power grid. Košice: TUKE

[2] Vranay, F., Vranayova, Z. \& Ocipova, D. (2010). Green energy and indoor technologies for smart buildings. In Ghafoori, N. (Eds.), Challenges, opportunities and solutions in structural engineering and construction. (pp. 869-872). London: CRC Press, Taylor \& Francis Group.

[3] Župová, L. (2013). Buildings energy efficiency in the context of modern methods of construction. In: Young Scientist 2013: The 5th PhD. Student Conference of Civil Engineering and Architecture, April 10 - 12, 2013. (p. 1-8). Košice: TUKE 
[4] Poorova, Z., Kaposztasova, D. \& Vranayova, Z. (2015). Natural and artificial green design environment and its effect on people living and working in it. BTHLA Bothalia journal. Vol. 45 (issue no. 2), 10p. http://www.bthla-journal.org/issue.php? $\mathrm{v}=45 \& \mathrm{i}=2$

[5] Ramsden, E. \& Adams, J. (2008) Escaping the Laboratory: The Rodent Experiments of John B. Calhoun \& Their Cultural Influence, The Journal of Social History. Vol. 23 (issue no. 8), 59p. http://www.lse.ac.uk/economicHistory/pdf/FACTSPDF/2308Ramadams.pdf

[6] SEPS (Slovak Electricity Transmission System). (2013). Selected data about the transmission system in 2013. Retrieved January 20, 2015 from http://www.sepsas.sk/seps/OdborUkazovatele. asp?kod=19

[7] Taiwan Power Company (2012). Sustainability Report 2012. Taipei, Taiwan: Taipower, Retrieved February 20, 2015 from http://info.taipower.com.tw/TaipowerWeb/upload/files/4/201 2e-all.pdf

[8] Statistical Office of the Slovak Republic (2013). Unemployment 2013. Retrieved January 16, 2015 from http://portal.statistics.sk/showdoc.do?docid $=67076$

[9] Employment agency of Slovak Republic. (2015) The rate of registered unemployment in regions of Slovak Republic for 2014. Retrieved March 20, 2015 from http://www.nup.sk/ 